
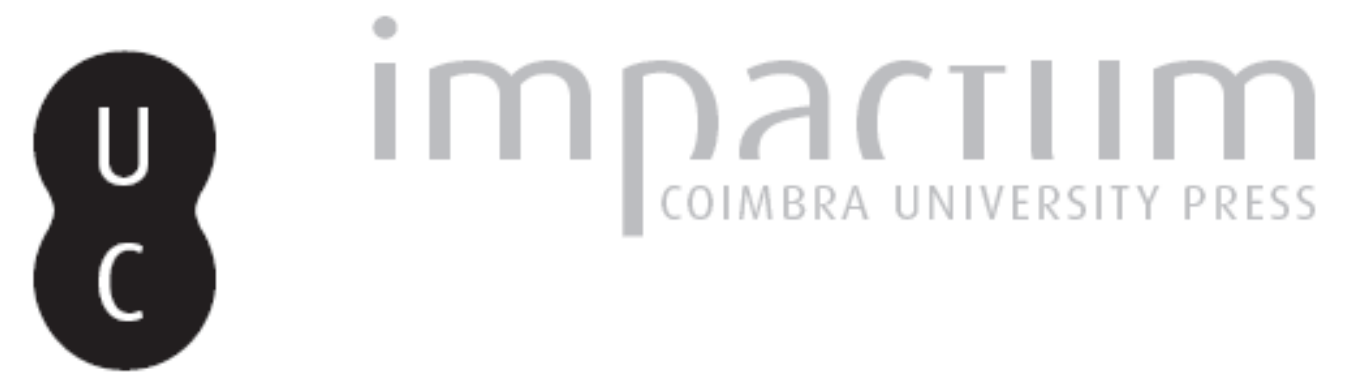

\title{
Dente de narval: um bastão de autoridade
}

Autor(es): Martins, Maria do Rosário

Publicado por: CIAS - Centro de Investigação em Antropologia e Saúde

URL persistente:

URI:http://hdl.handle.net/10316.2/41239

DOI:

DOI:http://dx.doi.org/10.14195/2182-7982_17_3

Accessed : $\quad$ 26-Apr-2023 11:13:53

A navegação consulta e descarregamento dos títulos inseridos nas Bibliotecas Digitais UC Digitalis, UC Pombalina e UC Impactum, pressupõem a aceitação plena e sem reservas dos Termos e Condições de Uso destas Bibliotecas Digitais, disponíveis em https://digitalis.uc.pt/pt-pt/termos.

Conforme exposto nos referidos Termos e Condições de Uso, o descarregamento de títulos de acesso restrito requer uma licença válida de autorização devendo o utilizador aceder ao(s) documento(s) a partir de um endereço de IP da instituição detentora da supramencionada licença.

Ao utilizador é apenas permitido o descarregamento para uso pessoal, pelo que o emprego do(s) título(s) descarregado(s) para outro fim, designadamente comercial, carece de autorização do respetivo autor ou editor da obra.

Na medida em que todas as obras da UC Digitalis se encontram protegidas pelo Código do Direito de Autor e Direitos Conexos e demais legislação aplicável, toda a cópia, parcial ou total, deste documento, nos casos em que é legalmente admitida, deverá conter ou fazer-se acompanhar por este aviso. 


\section{Antropologia Portuguesa}

$16-17 \cdot 1999-2000$

Departamento de Antropologia | Universidade de Coimbra 


\title{
Dente de narval - um bastão de autoridade
}

\author{
Maria do Rosário Martins \\ Museu Antropológico \\ Universidade de Coimbra \\ 3000-056 Coimbra, Portugal \\ martinsr@ci.uc.pt
}

\section{Resumo}

Este estudo refere-se a um artefacto, símbolo do poder do início do século XIX, proveniente de Iquique, Chile, pertencente ao acervo do Museu Antropológico da Universidade de Coimbra (MAUC). A sua raridade e elegante acabamento artístico assentam na natureza do material em que é confeccionado, dente de narval, na inerente carga simbólica e no documento histórico selado a lacre, emitido pelo vice-cônsul de Portugal em Iquique, relatando a origem e o percurso deste bastão de autoridade desde 1807.

\section{Palavras- chave}

Narval, bastāo, autoridade, símbolo do poder, Chile

\begin{abstract}
This study analyses an artifact from Iquique (Chile) which is todaly preserved in the Anthropological Museum of the University of Coimbra. The staff, an important power symbol dates from the beginning of the 19th century and is made of narwhal tooth. The rarity of the material and its artistic elegance convey strong symbolic meaning. The importance of the staff is further strengthened by an historical document, with the wax seal of the Portuguese vice-consul in Iquique which describes the origin and history of the piece since 1807 .
\end{abstract}

\section{Key words}

Narwhal, staff, authority, symbol of power, Chile 


\section{As origens e os mitos}

Da ordem dos cetáceos, família dos Monodontidae, espécie Monodon monoceros, o narval foi conhecido na Idade Média como o lendário "licorne ou unicórnio dos mares". A sua particularidade mais extraordinária assenta nos dois dentes que possui situados na maxila superior. Quando os machos têm cerca de um ano de idade, o dente do lado esquerdo eclode para se transformar na "presa", com um comprimento médio de 2 metros e raramente mais de 1,2 metros para as fêmeas; contudo, em cerca de 1 em 500 machos, ambos os dentes eclodem para formar uma dupla "presa" (Carwardine, 1995). Esta espécie habita na área circumpolar ártica atingindo em adulto um tamanho entre os 4 e 6 metros. Destacase pelo seu dente longo e espiralado, utilizado no combate e domínio pelas fêmeas e como ostentação visual de força (Whitfield, 1986).

Vários foram os mitos que povoaram o espírito humano associados ao unicómio terrestre e dos mares, esse imaginário animal misterioso ou monstruoso. A sua representação alegórica através de imagens, pinturas e tapeçarias mostra claramente o envolvimento do unicórnio em atmosferas aristocráticas e medievais podendo, ainda hoje, serem admirados alguns exemplares em museus da Europa. Como qualquer figura mitológica o seu aspecto estrutural é híbrido variando consoante o espaço e a época em que foi venerado ou temido.

Ao longo dos tempos o narval foi caçado devido à beleza do seu dente, pensando-se mesmo que este possuía qualidades mágicas e poderes medicinais. Mas, para além deste imaginário que lhe foi atribuído, o dente de narval foi utilizado no fabrico de objectos ligados à realeza e ao sagrado tais como, báculos, ceptros, tabaqueiras, taças, peças de adorno e amuletos. Actualmente a sua captura está protegida, limitando-se a caça à sobrevivência de alguns povos como os Esquimós que, apesar do inegável valor comercial do dente em marfim, apreciam sobretudo a carne, a gordura e a pele desta espécie, não atribuindo qualquer virtude curativa ou mítica à sua presa. Contrariamente aos Esquimós os povos escandinavos não consumiam a carne de narval por esta transmitir doenças mortais ao homem (Speculum regale). Com efeito, pensavam que este cetáceo se alimentava de carne em putrefacção: a palavra narwhal em escandinavo antigo significava "baleia devoradora de cadávres". Caçavam o narval 
apenas pela sua defesa que comercializavam fazendo-ia passar como corno de unicórnio (Didrit, 1996).

Pensa-se que o seu nome teve origem na Dinamarca, narhwal - baleia com nariz (Costa, 1997). Do alemão namwal, de nar, nariz e wall, baleia (Grande Enciclopédia Portuguesa e Brasileira, 1960).

\section{O artefacto}

O presente trabalho dá notícia precisamente de um artefacto, bastão ou bengala de autoridade, confeccionado em dente de narval, espiralado, sem polimento, com $89 \mathrm{~cm}$ de comprimento, adelgaçando para a ponta, em forma de bico. O punho em formato de coroa, cinta e ponteira são trabalhados em prata, decorados com motivos florais e em grega, friso decorativo composto pela combinação de linhas rectas, finamente cinzelados (figura $1 \mathrm{~A}$ e $\mathrm{B}$ ).
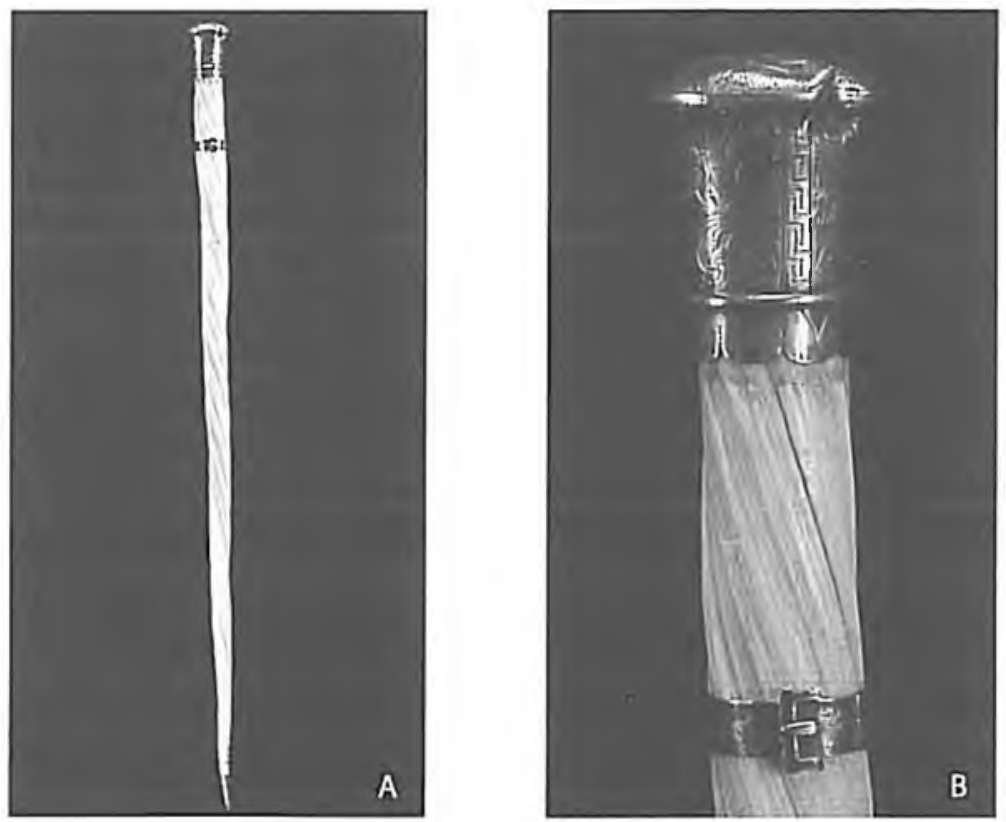

Figura 1. A. Bastăo de autoridade em dente de narval (lquique, Chile)

B. Pormenor do punho e da cinta

( N.. inv. MAUC - 90.10.18). 
Este objecto fez-se acompanhar por um documento inédito em acervos museológicos, manuscrito em espanhol, selado a lacre com carimbo do vice-cônsul de Portugal em Iquique (figura 2).

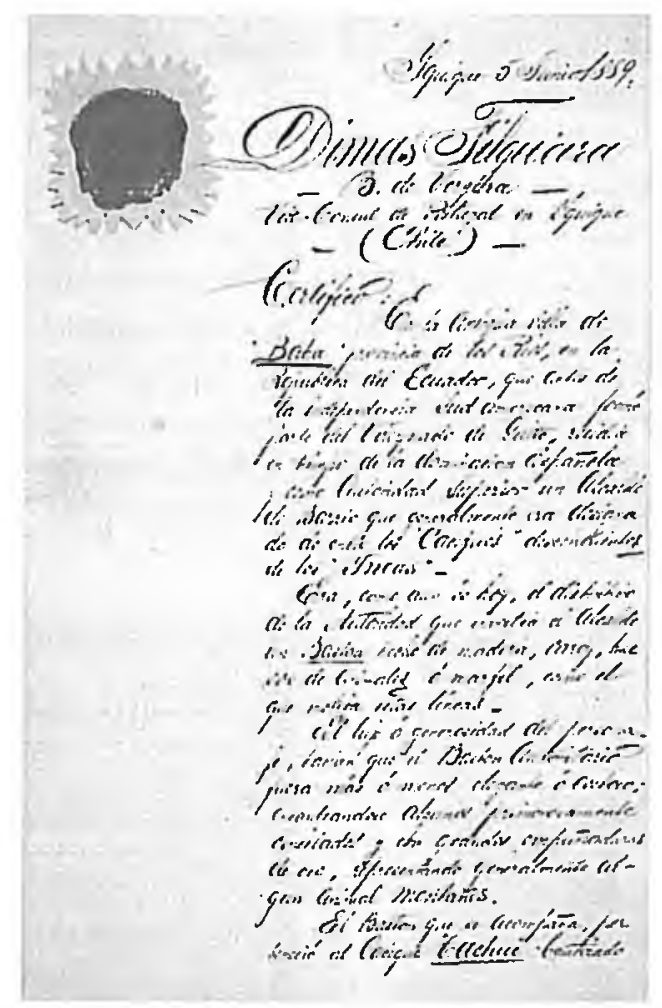

Figura 2. Frontispicio do documento do vice-cônsul de Portugal em Iquique (Chile).

O certificado revela o percurso histórico desde 1807 até à data em que o próprio vice-cônsul de Portugal em Iquique (Chile), Dimas Filgueira, em 5 de Junho de 1889 , tem a honra de o ofertar à ilustre Universidade de Lisboa para um Museu, conforme consta da nossa tradução: 
Iquique, 5 de Junho de 1889

Dimas Filgueira

B. de Vergara

Vice-Cônsul de Portugal em Iquique (Chile)

Certifico: Na antiga vila de "Baba" província dos Rios, na República do Equador que, antes da independência Sul americana formou parte do Vice-reinado de Quito, residia no tempo da dominaçāo Espanhola e como Autoridade Superior um Alcaide de Bairro que geralmente era designado entre os "Caciques" descendentes dos "Incas".

Era, como ainda é hoje, o distintivo da Autoridade que investia o Alcaide um Bastão feito de madeira, carapaça de tartaruga, osso de animais ou marfìm, como o que deu motivo a estas linhas.

O luxo ou generosidade da personagem, faziam com que o Bastāo de Autoridade fosse mais ou menos elegante ou caro, encontrando-se alguns primorosamente cinzelados e com grandes empunhaduras de ouro, representando geralmente algum animal montanhês.

O Bastão que se acompanha, pertenceu ao Cacique Tachui, baptizado Manuel Cepeda o qual foi alcaide dos Índios na referida Vila de Baba, lá pelos anos de 1807 a 1818 , herdando-o de seu pai "Tachui o velho".

Depois da independência do Equador da Metrópole, desempenhou o cargo de Chefe Tenente Paroquial de Vincas, cabeceira do Cantão com o mesmo nome na citada Província dos Rios.

O Bastão a que me refiro é de marfim sem polimento, retirado segundo a tradiçāo das mandíbulas ou barbatanas de uma grande baleia, e tem a forma natural de uma espiral. O punho e a ponteira são de prata cinzelada, e vieram a substituir os que teve primitivamente, pois por motivo da instauraçāo do Regime Republicano no Equador, tratou-se de inovar tudo o que era antigo. Posteriormente ao ano de 1820 foram colocados agregando-se depois uma cinta de prata destinada a suster as borlas que ainda hoje é costume usarem as Autoridades na América.

Além do mérito como objecto histórico tem o Bastão de Tachui um valor intrinseco de mais de $\$ 100$ (cem pesos) pois o material e trabalhos feitos nele, custam talvez mais que esta soma. A empunhadura e cinta são um trabalho bastante acabado e elegante apesar de serem feitos por ourives indígenas.

Este Bastão foi dado como pagamento em 1846 a um comerciante de Guayaquil (Equador) por uma soma de $\$ 80$ (oitenta pesos) e um dos seus parentes conservou-o até ao momento em que foi adquirido por aquele que subscreve e que agora deseja ter o gosto de o oferecer à ilustre Universidade de Lisboa para o seu Museu.

Iquique acima datado

Dimas Filgueira

Vice-Cônsul 
Por razões que desconhecemos quis o destino que o pequeno núcleo de espécimes museológicas provenientes de Iquique, oferecidas por Dimas Filgueira, incluindo o bastão de autoridade estudado, fosse integrado no Museu Antropológico da Universidade de Coimbra (MAUC), provavelmente desde o início do século XX, conforme consta do inventário de 1909, redigido por Adolfo Frederico Moller.

\section{Bibliografia}

Carwardine, M. 1995. Baleias, golfinhos e botos. Venda Nova, Bertrand Editora. Costa, J. A.; Melo, A. S. 1997. Dicionário da Lingua Portuguesa. Porto, Porto Editora.

Didrit, M. 1996. Licome de Mer on Licome de Terre: le Nan'al. Maitrise d'Anthropologie Sociale et Culturelle. Paris, Sorbonne. URL: htip://www.perso. club-internet.fr/nicus/Licome3.htm [Acedido em 2001/10/10].

Grande Enciclopédia Portuguesa e Brasileira 1960. Lisboa, Ed. Enciclopédia Limitada, Vol. XVIII.

Moller, A. F. [1909? Inventário das Colecções do Museu Antropológico da Universidade de Coimbra]. Documento manuscrito existente no Museu Antropológico da Universidade de Coimbra.

Whitfield, P. (coord.) 1986. Moderna Enciclopédia de animais. Mamíferos e aves. Lisboa, Círculo de Leitores, Vol. I. 